\title{
Analyses of Control Over the Gross Discharge of Regional Air Pollutants
}

\author{
Zong $\mathrm{Ke}^{1}$ and YuanYuan ${ }^{*}, 2$
}

\author{
${ }^{I}$ Shan Dong University of Science and Technology, Daizong Avenue, Taian City, Shandong, 271019, China \\ ${ }^{2}$ TaiShan College, Yingbin Avenue, Taian City, Shandong Province, 271019, China
}

\begin{abstract}
Total quantity control is an important means and measure of protecting the quality of the air and environment. Generally speaking, the existing calculation of the total quantity in environmental control is discussed under assumptions in the closed system. This is largely inconsistent with the practical facts. In this paper, the region is regarded as an open environment system, Datong Economic Development Zone is taken as the background, and the quality control of the air and environment is taken as the objective. Next, the concentration contribution curve and distribution function of the dispersal of air pollution sources are analyzed, the share and proportion of contribution of the interior and exterior pollution sources of the development zone are calculated. An optimization model of the total pollutant discharge is constructed, and the total quantity of pollutant discharged by the development zone is measured, calculated and analyzed.
\end{abstract}

Keywords: Air pollution, open system, optimization model, total quantity control.

\section{INTRODUCTION}

With the continuous development of China's economy, under the action of various factors, such as scale economy, industrial chain and environmental management, urban industrial zones have been developed and improved rapidly [14]. After the implementation of urban regionalization and functional reorientation, such measures as enterprise relocating and technical transformation have been taken to gradually relieve and evaporate the air pollution in the original urban areas. Instead, the industrial zones are concentrated together, so that the urban planning and functional layout is more rational. The concentrated distribution of industrial enterprises enables pollution to be abated intensively, with the superiority of scale abatement able to be given play to. Meanwhile, enterprise cooperation and environmental management are facilitated as well, which is conductive to environmental protection [5-9]. However, the concentration of industrial enterprises has led to the concentration of industrial pollution sources and the increase of pollution intensity. As a result, the management method for emission concentration control has been unable to suppress and relieve the deterioration of environmental quality, so the control over pollutant discharge amount, accordingly, becomes an important method and means for protecting the environment and achieving the environmental quality control objective.

Total quantity control is one of the core contents of regional environmental impact assessment. Total quantity control falls into two forms [10-12]: management target control and environmental quality target control. For the old industrial regions in which air environment quality has been seriously deteriorated, management target control is primarily adopted, to make a control plan for gradual reduction, to prevent the continuous deterioration of the environmental quality and improve the environmental quality gradually, so as to achieve the quality control target finally. For the emerging industrial zones with good environmental quality, environmental quality target control is directly adopted.

Owing to the dynamic flow of air and the dispersal of pollution, the total pollutant discharge amount in industrial zones or economic development zones is affected not only by such factors as weather, climate, terrain, landform and pollution source distribution, but also by environmental background and extra-zone pollution sources. Especially, the pollutions in the industrial concentration districts are superposed, to jointly affect the air environment quality. As a result, the total pollutant discharge amounts inside and outside the industrial zones interact with each other. Therefore, regional air environment system is an open system. To determine the influence relation and degree of the air pollutants in two adjacent industrial zones or the interaction among the pollution sources outside and inside an economic development zone is a precondition to determine the total quantity of regional air pollutants discharged. Next, we'll take Datong Economic Development Zone for example, to discuss the interaction among the pollution sources outside and inside the zone, as well as the determination method for the total quantity of regional air pollutants discharged and controlled.

\section{A SIMUlation ANALYSIS OF POLlUtion DIFFUSION IMPACT}

\subsection{Calculation Mode of Pollution Diffusion}

The annual or quarterly average concentration $C_{i}(x, 0)$ of any wind direction $i$ in Location $x$ downwind from exhaust funnel can be calculated by the following equation:

$$
C_{i}(x, 0)=\sum_{j}\left(\sum_{k} \bar{C}_{i j k} f_{i j k}+\sum_{k} \bar{C}_{L i j k} f_{L i j k}\right)
$$


In the equation (1), $f_{i j k}$ and $f_{L i j k}$ refer to the joint frequency of stability, and $\bar{C}_{i j k}$ refers to the concentration value that corresponds to this joint frequency in Point $\mathrm{X}$ down the wind. It can be calculated by the following equation (2) (3):

$$
\begin{aligned}
& F=\sum_{n=-k}^{+k}\left\{\exp \left[-\frac{(2 n D-H e)^{2}}{2 \sigma_{z}^{2}}\right]+\exp \left[\frac{(2 n D+H e)^{2}}{2 \sigma_{z}^{2}}\right]\right\} \\
& \bar{C}_{j i k}=\frac{Q}{(2 \pi)^{3 / 2} U \sigma_{z}(X / n)} \cdot F
\end{aligned}
$$

In the equation (2) (3), F is determined by the above method and $\mathrm{n}$ is the bearing value of wind direction. Let $\mathrm{n}=16 ; \mathrm{j}$ and $\mathrm{k}$ are the serial number of stability and wind speed section respectively, and $\bar{C}_{L i j k}$ is calculated in the same way as $\mathrm{C}$.

\subsection{The Location and Layout of Economic Development Zone}

Datong is the second largest city in Shanxi, located in the triangle zone encircled by Shanxi, Hebei and Inner Mongolia. It's a famous "coal city" in China. Datong Economic Development Zone is a provincial-level economic development zone approved by Shanxi Provincial Government in 1992, situated by Wenying Lake, to the southeast of the downtown area and 6 kilometers away from it. It's a flat land with favorable traffic conditions. The planned development area is 7 square kilometers, and the far-seeing plan is controlled within 10 square kilometers.

The development zone is mainly concentrated in a region with an area of 7.5 kilometers around Fan Village and Weizhoutong Village. In the surrounding region there are Shuipo Temple, Xiejiazhuang Village and East Wangzhuang Village, which are about 3 kilometers away from the development zone in WNW, about 2.5 kilometers away from the development in SSW and about 3.5 kilometers away from the development zone in ESE respectively. The industrial enterprises are relatively concentrated in Shuipo Temple, surrounded by farming area. The air pollution source in the development zone is the primary pollution source in this region. In addition, the industrial enterprises in Shuipo Temple also produce some impacts on the peripheral air environment quality. The development zone is downwind from Shuipo Temple in WNW, and the total air pollution discharge quantity is restricted by the industrial pollution in Shuipo Temple. Conversely, Shuipo Temple is downwind from the development in ESE, and the total air pollution discharge quality is also affected by the source of pollution in the development zone.

\subsection{A Simulation Analysis on the Trend of Pollution Diffusion}

The use of the conventional meteorological monitoring data of Datong City in three consecutive years and the above calculation pattern can calculate the contribution factor of a point source for monthly, quarterly and yearly average concentration in all the downwind districts. ESE and WNW are the main prevailing wind directions in this region. Their frequency is $6.69 \%$ and $5.58 \%$ respectively, followed by NW, which occupies $5.16 \%$. Use the meteorological data and the relevant parameters [13] to calculate and draw the trend of the contribution to the annual average concentration (the contribution of discharge $100 \mathrm{~g} / \mathrm{s}$ to the concentration of ground air pollutants is $\left.\mathrm{mg} / \mathrm{Nm}^{3}\right)$, as shown in Figs. $(\mathbf{1}, \mathbf{2})$. The impact trend of pollution diffusion takes the distance point at the maximum impact value as the demarcation point, with the inner and outer sides distributed in negative exponential order. The distribution function of the contamination effect can be given through negative exponential fit or by the direct use of interpolating polynomial.

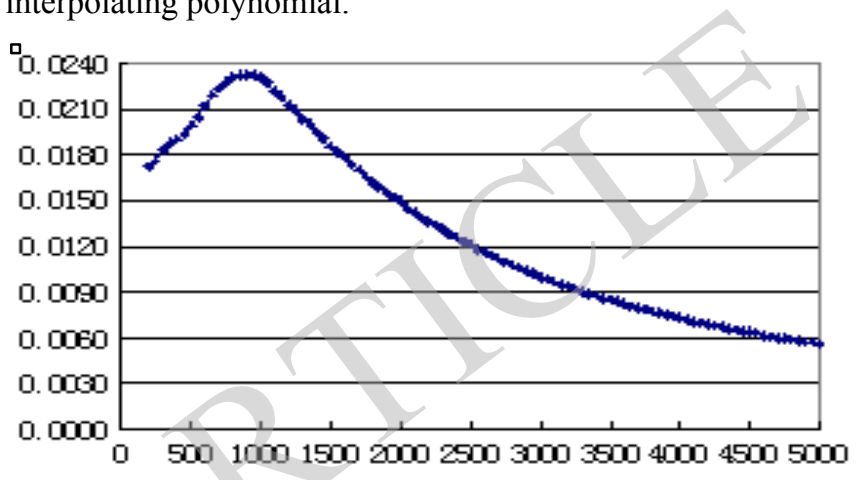

Fig. (1). Secular trend of the contribution to the annual average concentration down the wind in ESE.

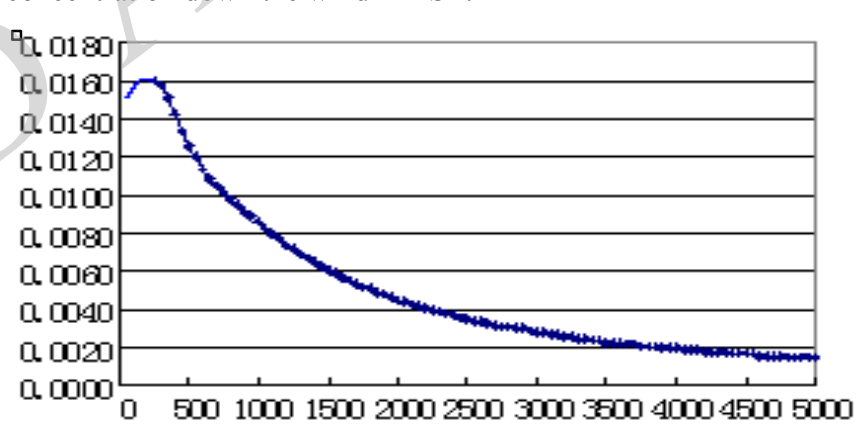

Fig. (2). Secular trend of the contribution to the annual average concentration down the wind in WNW.

(1) Negative exponential fit: make use of least square method to determine the distribution function of some downwind impact trend, which is

$y=f(x)= \begin{cases}Q K_{1} e^{a_{1} x} & \text { Inner side } \\ Q K_{2} e^{a_{2} x} & \text { Outer side }\end{cases}$

that is, the contribution of the pollution source, whose source strength is $Q(\mathrm{~kg} / \mathrm{h})$, to the site $\mathrm{x}$ meters away down the wind is $y=f(x)$.

(2) Interpolating polynomial: let $\left(x_{i}, y_{i}\right), i=1,2, \cdots, n$ refers to $\mathrm{n}$ analog computation discrete points, then the polynomial function of some downwind pollution contribution distribution should be:

$y=f(x)=Q \sum_{i=1}^{n} \frac{W_{i}(x)}{W i\left(x_{i}\right)} y_{i}$, and $W_{i}(x)=\prod_{j \neq i}\left(x-x_{i}\right)$ 
The pollution contribution functions shown in Figs. $(\mathbf{1}, \mathbf{2})$ are expressed as $f_{1}(x), f_{2}(x)$. After fitting calculation based on least square method, the following are obtained: specific quarterly standard value. This case is obtained through conversion according to the standard for quarterly calculation. The computational formula is $C_{1} / C_{2}=\left(t_{2} / t_{1}\right)^{\alpha}$,

$$
\begin{aligned}
& f_{1}(x)=\left\{\begin{array}{cc:c}
Q \times 1.5883 \times 10^{-4} \exp \left(4.6305 \times 10^{-4} x\right) & \text { Inner side }(x \leq 900 \mathrm{~m}) & \text { Regression } R^{2}=0.9899 \\
Q \times 3.0826 \times 10^{-4} \exp \left(-3.5791 \times 10^{-4} x\right) & \text { Outer side }(x>900 m) & \text { Regression } R^{2}=0.9909
\end{array}\right. \\
& f_{1}(x)=\left\{\begin{array}{cc:c}
Q \times 1.5883 \times 10^{-4} \exp \left(4.6305 \times 10^{-4} x\right) & \text { Inner side }(x \leq 900 m) & \text { Regression } R^{2}=0.9899 \\
Q \times 3.0826 \times 10^{-4} \exp \left(-3.5791 \times 10^{-4} x\right) & \text { Outer side }(x>900 m) & \text { Regression } R^{2}=0.9909
\end{array}\right.
\end{aligned}
$$

\section{A OPTIMIZATION MODEL FOR TOTAL POLLUTION DISCHARGE QUANTITY}

The air pollutant discharge in the development zone and Shuipo Temple will affect the local environmental quality, and meanwhile will exert a cross influence on each other's environmental quality. The pollution discharge quantity in both places will thus restrict each other. In principle, the total amount of discharge in Shuipo Temple cannot impose too many restrictions on the development of the development zone. Nor can the total amount of discharge in the development zone expropriate too many opportunities for the development of Shuipo Temple. The total pollution discharge quantity in both regions should be optimized, allocated and utilized on the premise that the environmental quality of the two regions and the surroundings is guaranteed to achieve the objective of quality control.

\subsection{Environmental Background and the Objective of Environmental Quality Control}

Environmental background is the impact of natural geographical and geological environment on environmental quality. The development zone is located in a semi-arid region beyond the Great Wall, where sand blown by the wind has a great impact on the TSP concentration in the air pollutants. Based on the source analysis result [14] of Tianjin Dagang Petrochemical Industry Planning Zone and the environmental monitoring analysis result of Taiyuan City, two projects funded by National Nature Science Foundation, this research estimates and determines that the polluted environmental background value of TSP caused by sandstorm and natural dust is $45-50 \%$ of the secondary standard concentration of environmental quality, and determines $\bar{C}_{i j}^{0}$, the background contribution of each control point.

National Ambient Air Quality Standard has set different grades of daily and yearly mean standards, but hasn't set in which $C_{1}$ refers to the annual average daily value, $C_{2}$ refers to the daily average value, $t_{1}$ refers to the daily time value, and $t_{2}$ refers to the time value of the annual average daily value, equal to 365 . Determine $\alpha$ according to the above formula, and then determine monthly and quarterly standard values. In GB3095-1996 Secondary Standard, the standard conversion of TSP and $\mathrm{SO}_{2}$ is listed in Table $\mathbf{1}$.

\subsection{Analyses on the Share of Pollution Contribution in Environmental Quality}

The pollution contribution of environmental background, intra-zone pollution sources and extra-zone pollution sources determines the pollutant concentration in the regional air environment quality. Let environmental background concentration be $\bar{C}_{0}$, its share in environmental quality control standard $\alpha_{0}=\overline{C_{0}} / C_{0}$, the concentration contribution portion of the local pollution sources and the pollution sources in Shuipo Temple in the pollution contribution of the environmental quality control points within the development zone be $x_{1}, y_{1}$, the concentration contribution portion of the local pollution sources and the pollution sources in the development zone in the pollution contribution of the environmental quality control points within Shuipo Temple be $x_{2}, y_{2}$, the transfer coefficient of pollution from the development zone to Shuipo Temple be a, the transfer coefficient of pollution from Shuipo Temple to the development zone be $b$, that is, there are relationships $y_{1}=b x_{2}, y_{2}=a x_{1}$, then there is the following relationship:

$$
\left\{\begin{array}{c}
x_{1}+y_{1} \leq 1-\alpha_{0} \\
x_{2}+y_{2} \leq 1-\alpha_{0} \\
y_{1}=b x_{2} \\
y_{2}=a x_{1}
\end{array}\right.
$$

Then,

Table 1. Target of ambient air quality control.

\begin{tabular}{|c|c|c|c|c|}
\hline Pollutant & Annual Average Daily Value & Quarterly Average Daily Value & Monthly Average Daily Value & Daily Average Value \\
\hline \hline TSP & 0.20 & 0.22 & 0.24 & 0.30 \\
\hline $\mathrm{SO}_{2}$ & 0.06 & 0.071 & 0.088 & 0.15 \\
\hline
\end{tabular}




$$
\left\{\begin{array}{lll}
y_{1} \leq \frac{b\left(1-\alpha_{0}\right)(1-a)}{1-a b}, & x_{1} \geq \frac{\left(1-\alpha_{0}\right)(1-b)}{1-a b}, & x_{1}+y_{1} \leq 1-\alpha_{0} \\
y_{2} \leq \frac{a\left(1-\alpha_{0}\right)(1-b)}{1-a b}, & x_{2} \geq \frac{\left(1-\alpha_{0}\right)(1-a)}{1-a b}, & x_{2}+y_{2} \leq 1-\alpha_{0}
\end{array}\right.
$$

The distance between the development zone and Shuipo Temple $\mathrm{L}=3500$ meters. If the pollution contribution function distribution in downwind ESE and WNW within this region is $f_{1}(x), f_{2}(x)$ respectively, then the transfer coefficient of the max influence from the development zone to Shuipo Temple $a=f_{1}(L) / \max \left(f_{1}(x)\right)=36.5 \%$, and the transfer coefficient of the max influence from the pollution sources in Shuipo Temple to the development zone $a=f_{2}(L) / \max \left(f_{2}(x)\right)=14.1 \%$. Substitute them into Formula (9) and get:

$$
\left\{\begin{array}{lll}
y_{1} \leq 0.094\left(1-\alpha_{0}\right), & x_{1} \geq 0.906\left(1-\alpha_{0}\right), & x_{1}+y_{1} \leq 1-\alpha_{0} \\
y_{2} \leq 0.331\left(1-\alpha_{0}\right), & x_{2} \geq 0.669\left(1-\alpha_{0}\right), & x_{2}+y_{2} \leq 1-\alpha_{0}
\end{array}\right.
$$

The result of the above formula shows that in the environmental quality of the development zone, the contribution of the local pollution sources in the development zone can account for $90.6 \%$ of the environmental capacity exclusive of environmental background, and the impact of Shuipo Temple on the development zone accounts for $9.4 \%$ of the rest environmental capacity. In the environmental standards of Shuipo Temple, the local pollution sources account for $66.9 \%$, and the impact of the development zone on it accounts for $33.1 \%$. The total pollution discharge quantity in the development zone and Shuipo Temple should be calculated on this basis.

\subsection{A Optimization Model for the Total Pollution Discharge Quantity}

(1) A calculation model for the discharge quantity inside and outside the development zone.

Let total pollution discharge quantity in the development zone and Shuipo Temple be $\mathrm{Q}_{1}, \mathrm{Q}_{2}$, then the successive model for the total discharge quantity control should be:

$$
\begin{aligned}
& \max Z=Q_{1}+Q_{2} \\
& Q_{1} f_{1}(x)+Q_{2} f_{2}(L-x) \leq C_{0}-\bar{C}_{0} \quad x \in(0, L) \\
& Q_{1} \geq Q_{10}, Q_{2} \geq Q_{20} \\
& Q_{1} \geq 0, Q_{2} \geq 0
\end{aligned}
$$

In the model, $f_{1}(x), f_{2}(x)$ are the distribution function of the pollution contribution in downwind ESE and WNW in 1.3, $\mathrm{L}$ is the maximum distance between the development zone and Shuipo Temple, $\mathrm{C}_{0}, \bar{C}_{0}$ are the target of air quality control and environmental background respectively, and $\mathrm{Q}_{10}$, $\mathrm{Q}_{20}$ are the minimum total amount of discharge in the development zone and Shuipo Temple. This model is a nonlinear planning problem, which can be solved by the optimizing method of multivariable function in constraint conditions, but the solving process is cumbersome. For convenient calculation, we can make a calculation after discretizing the model.

(2) An independent calculating model for the total quantity in the development zone.

Divide the air quality control region into $n_{1} \times n_{2}$ meshes by certain isometric intervals, and use the pollution contribution density in the center of each mesh to represent the pollution contribution in the mesh region. We might as well set up $n_{0}$ environmental sensitive control points as separate control points in special environmental sensitive areas, such as school, hospital and residential area. Then, the simulation and estimation model for the total air pollution discharge quantity in the development zone should be:

$$
\begin{aligned}
& \max Q=\sum_{k=1}^{m} Q_{k} \\
& \begin{cases}\sum_{k=1}^{m} C_{i j k} \leq C^{0}-C_{i j k}^{0}-\overline{C^{0}} & i=1,2, \cdots, n_{1} ; j=1,2, \cdots, n_{2} \\
\sum_{k=1}^{m} C_{k l} \leq C^{0}-C_{l}^{0}-\overline{C^{0}} & l=1,2, \cdots, n_{0} \\
Q_{k} \geq Q_{k}^{0} & k=1,2, \cdots, m \\
Q_{k} \geq 0 & k=1,2, \cdots, m\end{cases}
\end{aligned}
$$

In the model, $\mathrm{m}$ refers to the number of the pollution emission sources, $\mathrm{Q}_{\mathrm{k}}$ refers to the control emissions of the kth pollution source, $\mathrm{C}_{\mathrm{ijk}}$ and $\mathrm{C}_{\mathrm{kl}}$ are respectively the contribution density of the kth pollution source in the control points $(i, j), C_{i j}^{0}, C_{l}^{0}$ are separately the contribution density of the pollution sources outside the development zone in the control points $(i, j)$ and $l, C^{0}$ and $\bar{C}^{0}$ refer to the target of quality control and environmental background, and $Q_{k}^{0}$ refers to the minimum requirement for the pollutant discharge from the pollution sources.

\subsection{A Calculating Analysis on the Total Amount of Discharge in Datong Development Zone}

Make a statistical analysis on the conventional continuous meteorological monitoring data in the recent 3 years and obtain the data on the yearly, quarterly and monthly joint frequency. Make a calculation based on the independent calculating model for total quantity in the development zone. The total pollution discharge quantity and quarterly distribution in the development zone are indicated in Table 2, in which the result is designated as total demarcated control quantity. As shown in the table, the total annual discharge of TSP and $\mathrm{SO}_{2}$ in the development zone is 6,636.3 tons and 3,843.4 tons respectively. However, there is a great difference among the allowable discharge amounts in different season, so this requires that when the total air pollution discharge quantity is controlled, not only should the total quantity be controlled, but the reasonable temporal and spatial distribution of discharge should be controlled, because only in this way can it be ensured that the target of regional environmental quality control will be achieved. 
Table 2. The calculation result of total discharge amount.

\begin{tabular}{|c|c|c|c|c|}
\hline \multirow{2}{*}{ Season } & \multicolumn{2}{|c|}{ TSP } & \multicolumn{2}{c|}{ SO $_{2}$} \\
\cline { 2 - 5 } & $\begin{array}{c}\text { Discharge } \\
\text { (T) }\end{array}$ & $\begin{array}{c}\text { Ratio } \\
\text { (\%) }\end{array}$ & $\begin{array}{c}\text { Discharge } \\
\text { (T) }\end{array}$ & $\begin{array}{c}\text { Ratio } \\
\text { (\%) }\end{array}$ \\
\hline \hline Spring & 2224.6 & 33.52 & 1292.3 & 33.62 \\
\hline Summer & 1425.2 & 21.48 & 816.3 & 21.24 \\
\hline Fall & 1535.9 & 23.14 & 892.2 & 23.21 \\
\hline Winter & 1450.6 & 21.86 & 842.6 & 21.92 \\
\hline Four seasons & 6636.3 & 100 & 3843.4 & 100 \\
\hline
\end{tabular}

\section{CONCLUSION}

Ambient air system is a complex system, and the capacity of regional environmental air pollutants are affected by many factors, such as terrain, weather, landform, and pollution source distribution, etc. For a convenient research, box model is usually adopted, and Gaussian model is often used as a dispersal pattern. Air system is approximately regarded as a stable closed system, and this is greatly different from the reality. In this paper, environmental system is set as an open system, which breaks the assumption of closed system. A case analysis is carried out with Datong Economic Development Zone as an example, and the total discharge quantity of such major air pollutants as $\mathrm{SP}$ and $\mathrm{SO}_{2}$ in the development zone is figured out. The discussion is made in Gaussian model and stable meteorological conditions, without taking the impact of such factors as terrain, landform and changeable weather into adequate consideration. There may be some difference between the analysis result and real development, but it can yet be regarded as a basis for pollution control and a support for environmental decision making. Meanwhile, actual monitoring data can be taken as a basis in implementation process, to make necessary corrections and adjustments, so that the theoretical analysis result should be closer to the actual environmental conditions.

\section{CONFLICT OF INTEREST}

The authors confirm that this article content has no conflict of interest.

\section{ACKNOWLEDGEMENTS}

This paper sponsored by the China's Ministry of education of Humanities and social science project (14YJCZH236) and the 2014 Shandong Province Education Department of Humanities and Social Sciences project.

\section{REFERENCES}

[1] Gu, Q. Control Benchmark and Method for the Total Air Quantity in China Region. China Environ. Sci., 2010, 20(Suppl.), 25-28.

[2] Zhang, Z. Report on Environmental Impact Assessment in Datong Economic Development Zone. Shanxi University, 2012, 12.

[3] Zhu, T.; Bai, Z.; Zhu, X. The Application of Source Analysis Technology to Environmental Evaluation-Control over Regional Total Air Pollution. China Environ. Sci., 2013, 20(Suppl.), 2-6.

[4] Hankey, S.; Marshall, J.D.; Brauer, M. Health impacts of the built environment: within-urban variability in physical inactivity, air pollution, and ischemic heart disease mortality. Environ. Health Perspect., 2012, 120(2), 247-53

[5] Mackey, C.W.; Lee, X.; Smith, R.B. Remotely sensing the cooling effects of city scale efforts to reduce urban heat island. Build. Environ., 2011, 49, 348-358.

[6] Kan, H. Climate Change and Human Health in China. Environ Health Perspect., 2011, 119(2), A60-A61,

[7] Zhang, J.; Mauzerall, D.L.; Zhu, T.; Liang, S.; Ezzati, M.; Remais, J.V. Environmental health in China: progress towards clean air and safe water. The Lancet, 2010, 375(9720), 1110-1119.

[8] Agarwal, M.; Tandon, A. Modeling of the urban heat island in the form of mesoscale wind and of its effect on air pollution dispersal. Appl. Mathemat. Modell., 2010, 34(9), 2520-2530

[9] Sharan, M.; Kumar, P. An analytical model for crosswind integrated concentrations released from a continuous source in a finite atmospheric boundary layer. Atmosphe. Environ., 2009, 43(14), 2268-2277

[10] Gaffin, S.R.; Rosenzweig, C.; Khanbilvardi, R.; Parshall, L.; Mahani, S.; Glickman, H.; Goldberg, R.; Blake, R.; Slosberg, R.B.; Hillel, D. Variations in New York city's urban heat island strength over time and space. Theoret. Appl. Climatol., 2008, 94(1), 1-11.

[11] Fenger, J. Air pollution in the last 50 years - From local to global. Atmosph. Environ., 2008, 43(1), 13-22.

[12] Stern, R.; Builtjes, P.; Schaap, M.; Timmermans, R.; Vautard, R.; Hodzic, A.; Memmesheimer, M.; Feldmann, H.; Renner, E.; Wolke, R.; Kerschbaumer, A. A model inter-comparison study focussing on episodes with elevated PM10 concentrations. Atmosph. Environ., 2008, 42(19), 4567-4588.

[13] Simpson, R.; Williams, G.; Petroeschevsky, A.; Best, T.; Morgan, G.; Denison, L.; Hinwood, A.; Neville, G.; Neller, A. The shortterm effects of air pollution on daily mortality in four Australian cities. Aust. N. Z. J. Public Health, 2005, 29(3), 205-212.

Received: January 6, 2015

(C) Ke and Yuan; Licensee Bentham Open.

This is an open access article licensed under the terms of the Creative Commons Attribution Non-Commercial License (http://creativecommons.org/licenses/ by-nc/3.0/) which permits unrestricted, non-commercial use, distribution and reproduction in any medium, provided the work is properly cited. 